Supporting Information

\title{
Determination of Solubility of Sodium Salts in Aqueous Surfactant and STPP Solutions Using an Ion Selective Electrode
}

Xin Wang, ${ }^{\text {a }}$ Ya-Na Zhang, ${ }^{\text {a,b }}$ Yang-Xin Yu ${ }^{\text {a,c* } *}$

${ }^{a}$ Laboratory of Chemical Engineering Thermodynamics, Department of Chemical Engineering, Tsinghua University, Beijing 100084, People's Republic of China

${ }^{b}$ College of Chemical Engineering, Beijing University of Chemical Technology, Beijing 100029, P. R. China

${ }^{c}$ State Key Laboratory of Chemical Engineering, Tsinghua University, Beijing 100084, People's Republic of China

E-mail: yangxyu@ mail.tsinghua.edu.cn

Phone: $+86-10-62782558$ 
All the data of the EMFs not included in the main text are shown in the Figures S1-S11. Figures S1-S3 are the EMFs of single salts in aqueous systems at $298.15 \mathrm{~K}$. Figure $\mathrm{S} 4$ is the EMFs of the ternary system $\mathrm{Na}_{2} \mathrm{SO}_{4}+\mathrm{SDBS}+\mathrm{H}_{2} \mathrm{O}$. Figure $\mathrm{S} 5$ is the EMFs of the ternary system $\mathrm{Na}_{2} \mathrm{CO}_{3}+\mathrm{SDBS}+\mathrm{H}_{2} \mathrm{O}$. Figure $\mathrm{S} 6$ is the EMFs of the ternary system $\mathrm{NaCl}+\mathrm{SDBS}+\mathrm{H}_{2} \mathrm{O}$. Figure $\mathrm{S} 7$ is the EMFs of the ternary system $\mathrm{Na}_{2} \mathrm{SO}_{4}+\mathrm{SDS}+\mathrm{H}_{2} \mathrm{O}$. Figure $\mathrm{S} 8$ is the EMFs of the ternary system $\mathrm{Na}_{2} \mathrm{CO}_{3}+\mathrm{SDS}+\mathrm{H}_{2} \mathrm{O}$. Figure $\mathrm{S} 9$ is the EMFs of the ternary system $\mathrm{NaCl}+\mathrm{SDS}+\mathrm{H}_{2} \mathrm{O}$. Figure $\mathrm{S} 10$ is the EMFs of the ternary system $\mathrm{Na}_{2} \mathrm{SO}_{4}+\mathrm{STPP}+\mathrm{H}_{2} \mathrm{O}$. Figure $\mathrm{S} 11$ is the EMFs of the ternary system $\mathrm{NaCl}+\mathrm{STPP}+\mathrm{H}_{2} \mathrm{O}$. The data of the EMFs in Figures 3 to 7 are also tabulated in Table S1-S5.

Table S1. EMF of solution and logarithmic molality of $\mathrm{Na}_{2} \mathrm{SO}_{4}$ in water at 303.15K.

$\begin{array}{cc}\ln m_{\mathrm{N} 22 \mathrm{SO}} & \mathrm{EMF}(\mathrm{mV}) \\ 0.20854 & 39.4 \\ 0.34207 & 42.4 \\ 0.45985 & 45.1 \\ 0.56521 & 47.7 \\ 0.66052 & 50.0 \\ 0.74753 & 52.2 \\ 0.82758 & 54.4 \\ 0.90168 & 56.5 \\ 0.97068 & 58.4 \\ 1.03522 & 59.5 \\ 1.09584 & 59.7 \\ 1.15300 & 59.8 \\ 1.20707 & 59.9 \\ 1.25836 & 59.9 \\ 1.26831 & 59.9 \\ 1.27816 & 59.9 \\ 1.30715 & 59.9\end{array}$


Table S2. EMF of solution and logarithmic molality of $\mathrm{Na}_{2} \mathrm{CO}_{3}$ in $200 \mathrm{~g}$ water at $303.15 \mathrm{~K}$.

$\begin{array}{cc}\ln m_{\mathrm{Na} 2 \mathrm{CO}} & \mathrm{EMF}(\mathrm{mV}) \\ 0.50144 & 52.3 \\ 0.63497 & 55.9 \\ 0.75276 & 59.3 \\ 0.85812 & 62.4 \\ 0.95343 & 65.4 \\ 1.04044 & 68.4 \\ 1.12048 & 71.2 \\ 1.19459 & 74.0 \\ 1.26358 & 76.4 \\ 1.32812 & 77.4 \\ 1.35281 & 77.5 \\ 1.38874 & 77.6 \\ 1.44590 & 77.7 \\ 1.49997 & 77.7 \\ 1.51044 & 77.7 \\ 1.52080 & 77.7 \\ 1.53106 & 77.7\end{array}$

Table S3. EMF of solution and logarithmic molality of $\mathrm{NaCl}$ in water at 303.15K.

$\begin{array}{cc}\ln m_{\mathrm{NaCl}} & \mathrm{EMF}(\mathrm{mV}) \\ 1.63476 & 66.2 \\ 1.66755 & 68.3 \\ 1.69929 & 70.0 \\ 1.73007 & 72.1 \\ 1.75992 & 74.0 \\ 1.78891 & 75.7 \\ 1.80309 & 76.5 \\ 1.81708 & 76.7 \\ 1.83087 & 76.9 \\ 1.84448 & 77.0 \\ 1.85790 & 77.0 \\ 1.87114 & 77.0 \\ 1.88422 & 77.0 \\ 1.89712 & 77.0\end{array}$


Table S4. EMF of solution and logarithmic molality of $\mathrm{Na}_{2} \mathrm{SO}_{4}$ in $200 \mathrm{~g}$ water $+10 \mathrm{~g}$ SDBS solution at $298.15 \mathrm{~K}$.

$\begin{array}{cc}\ln m_{\mathrm{N} 22 \mathrm{SO} 4} & \mathrm{EMF}(\mathrm{mV}) \\ -0.34753 & 5.0 \\ 0.05861 & 11.1 \\ 0.3461 & 15.4 \\ 0.41324 & 16.4 \\ 0.46363 & 17.2 \\ 0.51700 & 17.9 \\ 0.53759 & 18.3 \\ 0.56939 & 18.7 \\ 0.59844 & 18.6 \\ 0.62785 & 18.5 \\ 0.66121 & 18.5 \\ 0.69700 & 18.5 \\ 0.74515 & 18.5\end{array}$

Table S5. EMF of solution and logarithmic molality of $\mathrm{NaCl}$ in $200 \mathrm{~g}$ water $+4 \mathrm{~g}$ STPP solution at $298.15 \mathrm{~K}$.

$\begin{array}{cc}\ln m_{\mathrm{NaCl}} & \mathrm{EMF}(\mathrm{mV}) \\ 0.94625 & 37.7 \\ 1.23214 & 48.7 \\ 1.34976 & 54.2 \\ 1.45573 & 58.4 \\ 1.55302 & 63.3 \\ 1.63668 & 67.2 \\ 1.72530 & 71.0 \\ 1.79016 & 74.9 \\ 1.86343 & 75.1 \\ 1.92272 & 75.1 \\ 1.95121 & 75.1 \\ 1.97259 & 75.1\end{array}$




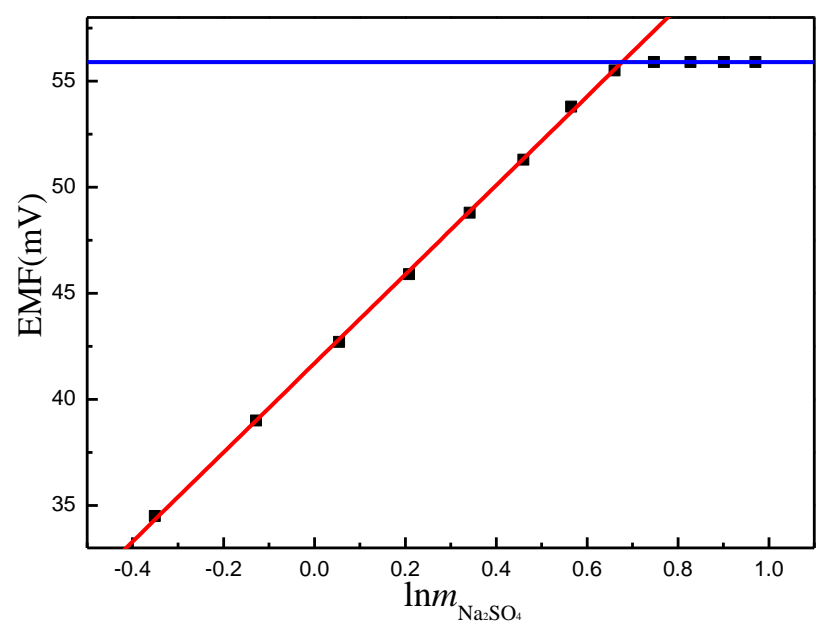

Figure S1. EMF of solution versus logarithmic molality of $\mathrm{Na}_{2} \mathrm{SO}_{4}$ in water at 298.15K. Squares refer to measured data and the lines are linearly fitted values.

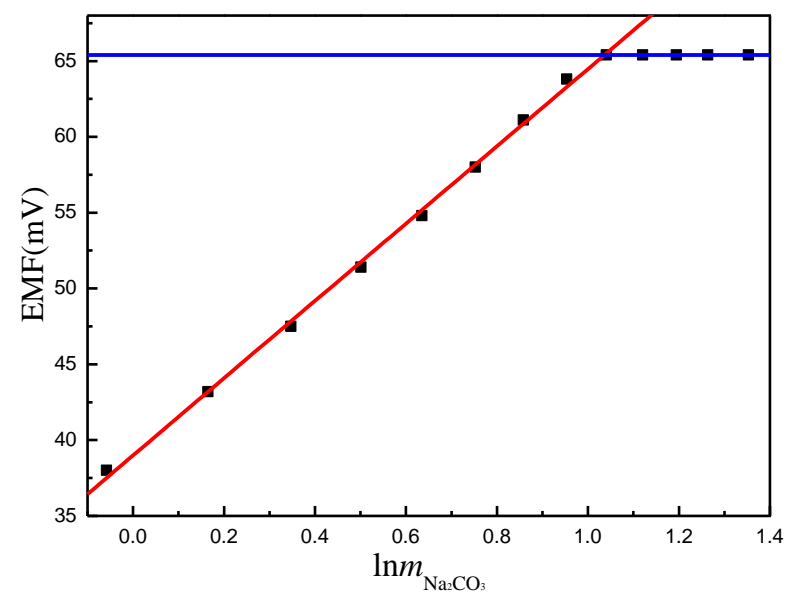

Figure S2. EMF of solution versus logarithmic molality of $\mathrm{Na}_{2} \mathrm{CO}_{3}$ in water at 298.15K. The lines and symbols have the same meaning as in Figure S1.

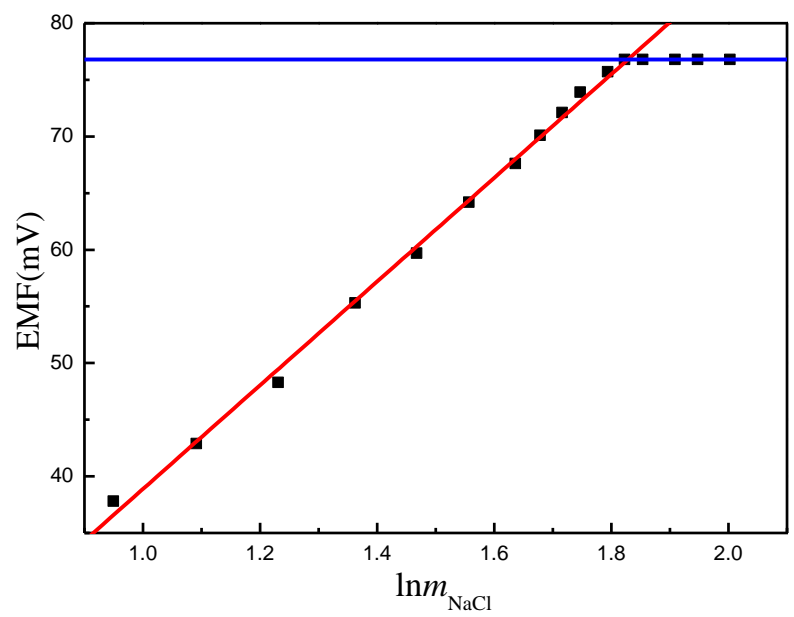

Figure S3. EMF of solution versus logarithmic molality of $\mathrm{NaCl}$ in water at $298.15 \mathrm{~K}$.

The lines and symbols have the same meaning as in Figure S1. 

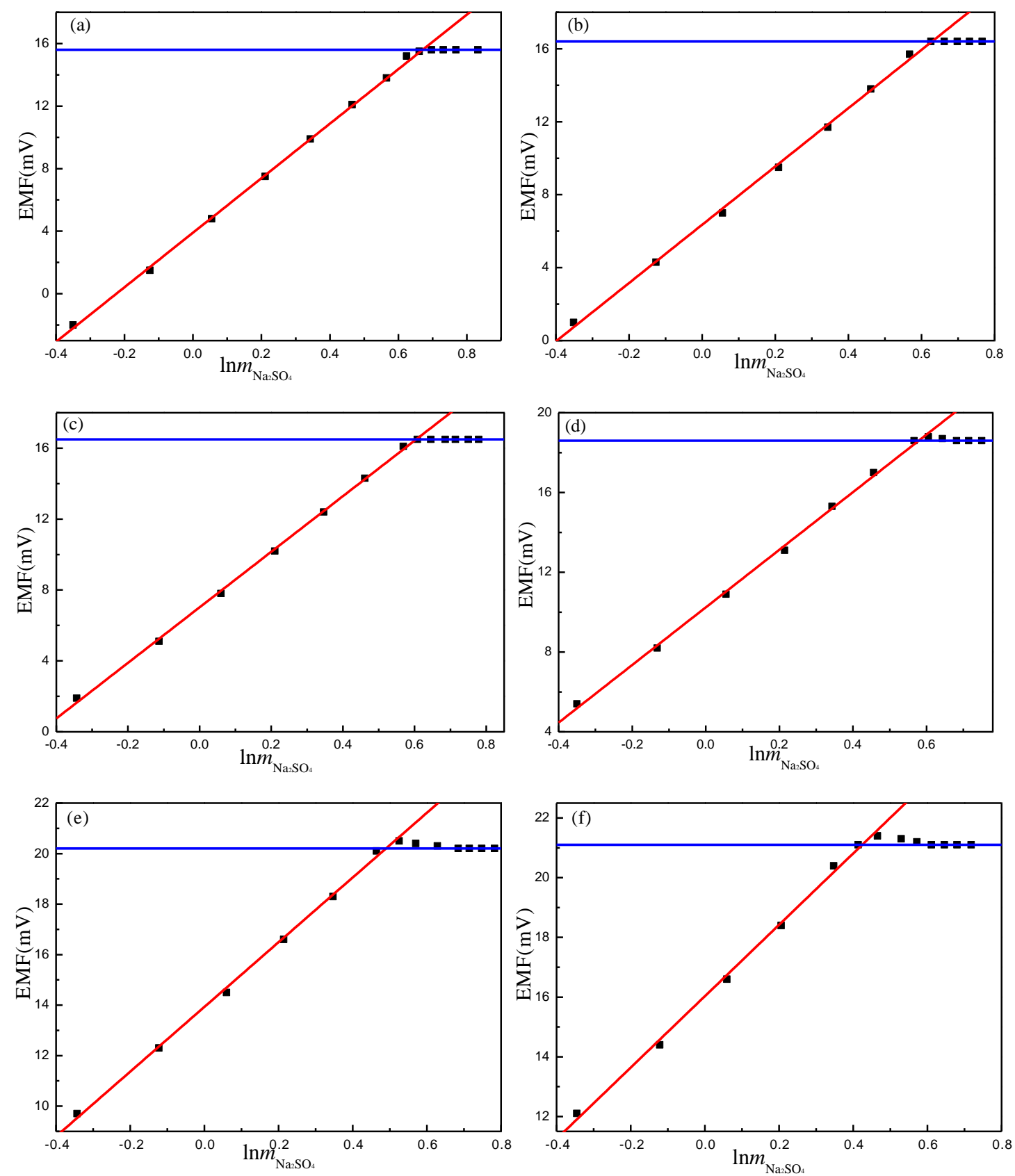

Figure S4. EMF of solution versus logarithmic molality of $\mathrm{Na}_{2} \mathrm{SO}_{4}$ in $200 \mathrm{~g}$ water plus (a) $2 \mathrm{~g}$, (b) 4g, (c) 6g, (d) 8g, (e) 13g, and (f) 16g SDBS solutions at $298.15 \mathrm{~K}$. The lines and symbols have the same meaning as in Figure S1. 

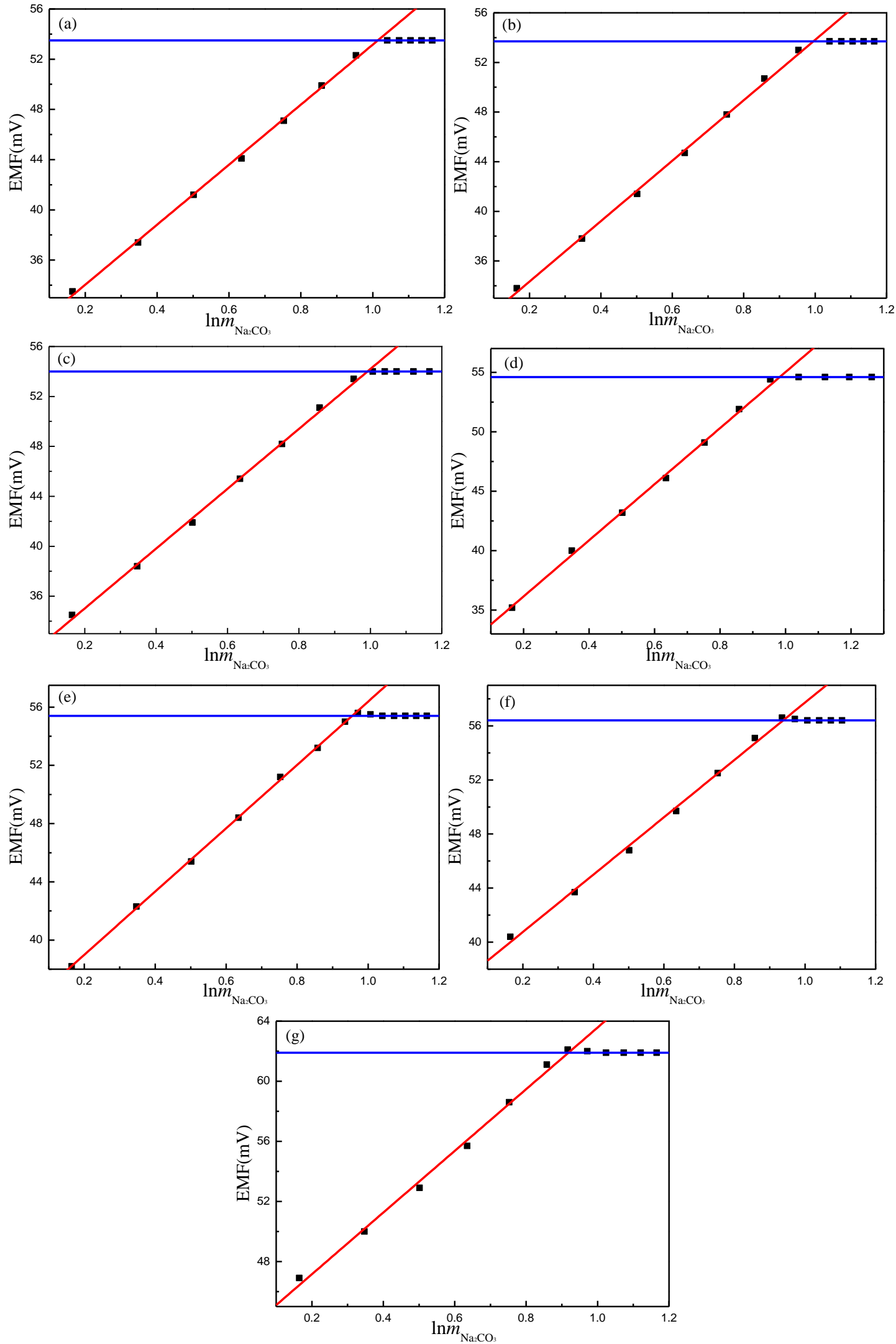

Figure S5. EMF of solution versus logarithmic molality of $\mathrm{Na}_{2} \mathrm{CO}_{3}$ in $200 \mathrm{~g}$ water plus (a) $2 \mathrm{~g}$, (b) $4 \mathrm{~g}$, (c) $6 \mathrm{~g}$, (d) $8 \mathrm{~g}$, (e) $10 \mathrm{~g}$, (f) $13 \mathrm{~g}$, and (g) $16 \mathrm{~g}$ SDBS solutions at 298.15 K. The lines and symbols have the same meaning as in Figure S1. 

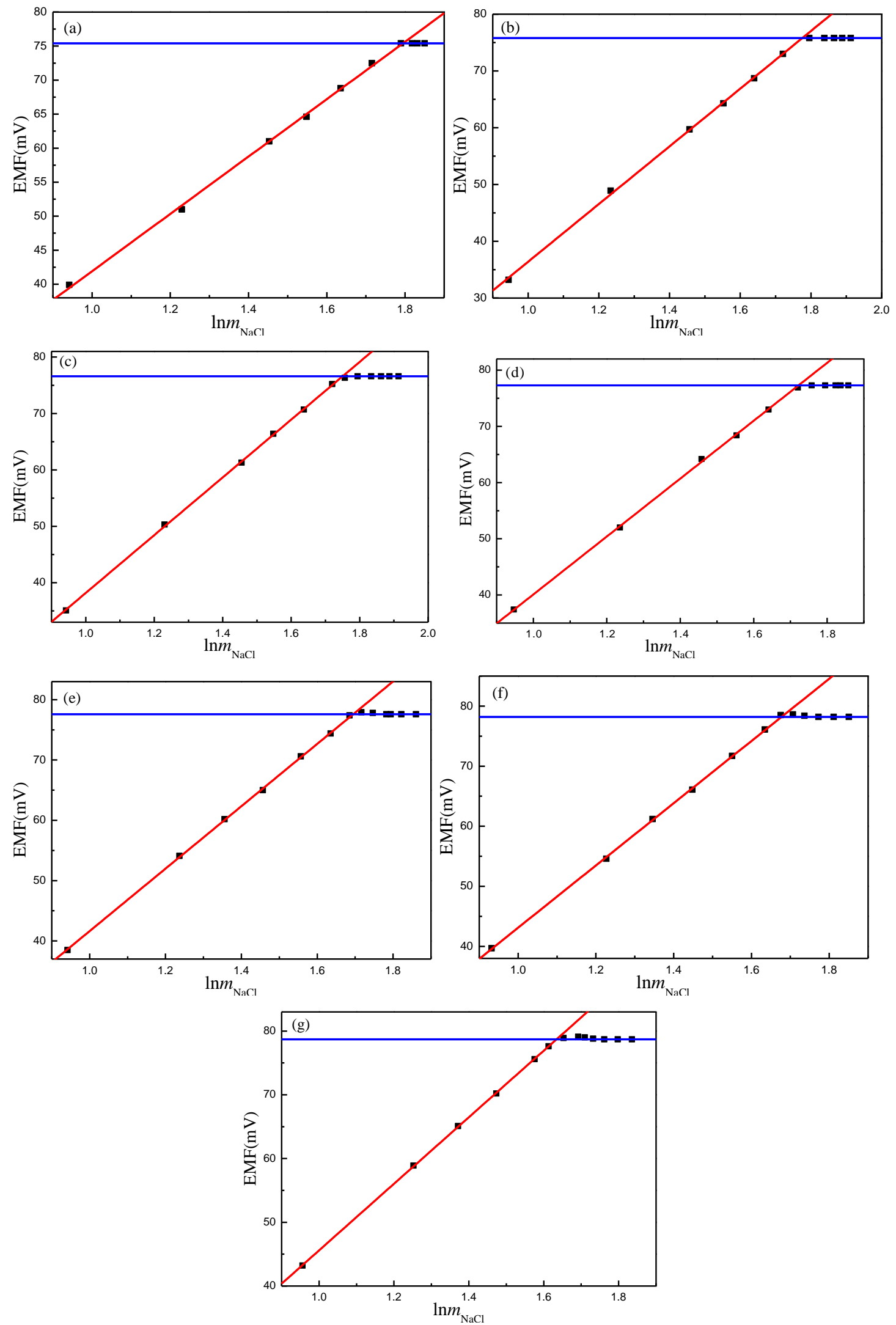

Figure S6. EMF of solution versus logarithmic molality of $\mathrm{NaCl}$ in $200 \mathrm{~g}$ water plus (a) $2 \mathrm{~g}$, (b) $4 \mathrm{~g}$, (c) 6g, (d) $8 \mathrm{~g}$, (e) $10 \mathrm{~g}$, (f) $12 \mathrm{~g}$, and (g) $16 \mathrm{~g}$ SDBS solutions at $298.15 \mathrm{~K}$. The lines and symbols have the same meaning as in Figure S1. 

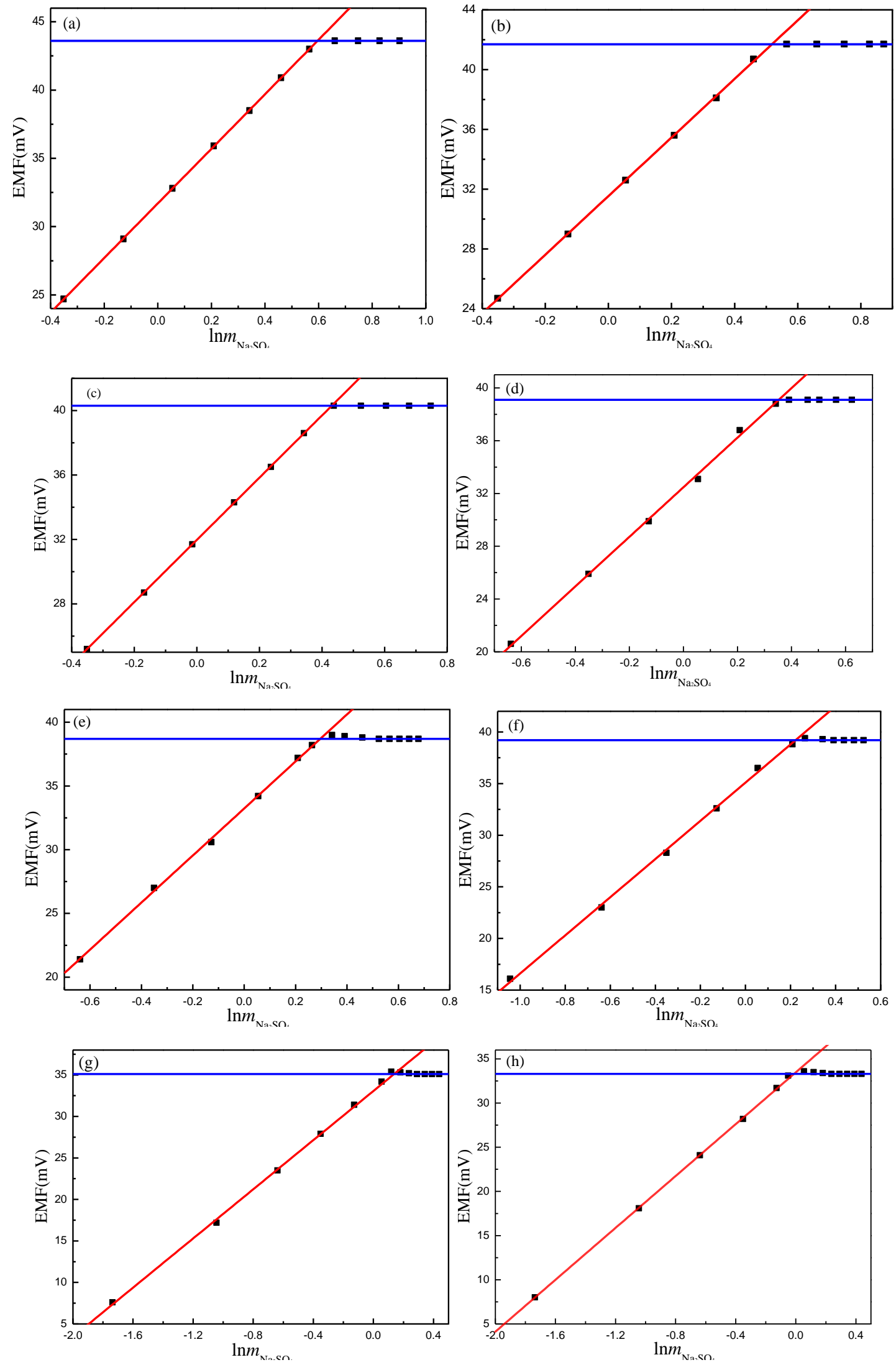

Figure S7. EMF of solution versus logarithmic molality of $\mathrm{Na}_{2} \mathrm{SO}_{4}$ in $200 \mathrm{~g}$ water plus (a) $2 \mathrm{~g}$, (b) 4g, (c) 6g, (d) $8 \mathrm{~g}$, (e) 10g, (f) 12g, (g) 15g, and (h) 20g SDS solutions at 298.15 K. The lines and symbols have the same meaning as in Figure S1. 

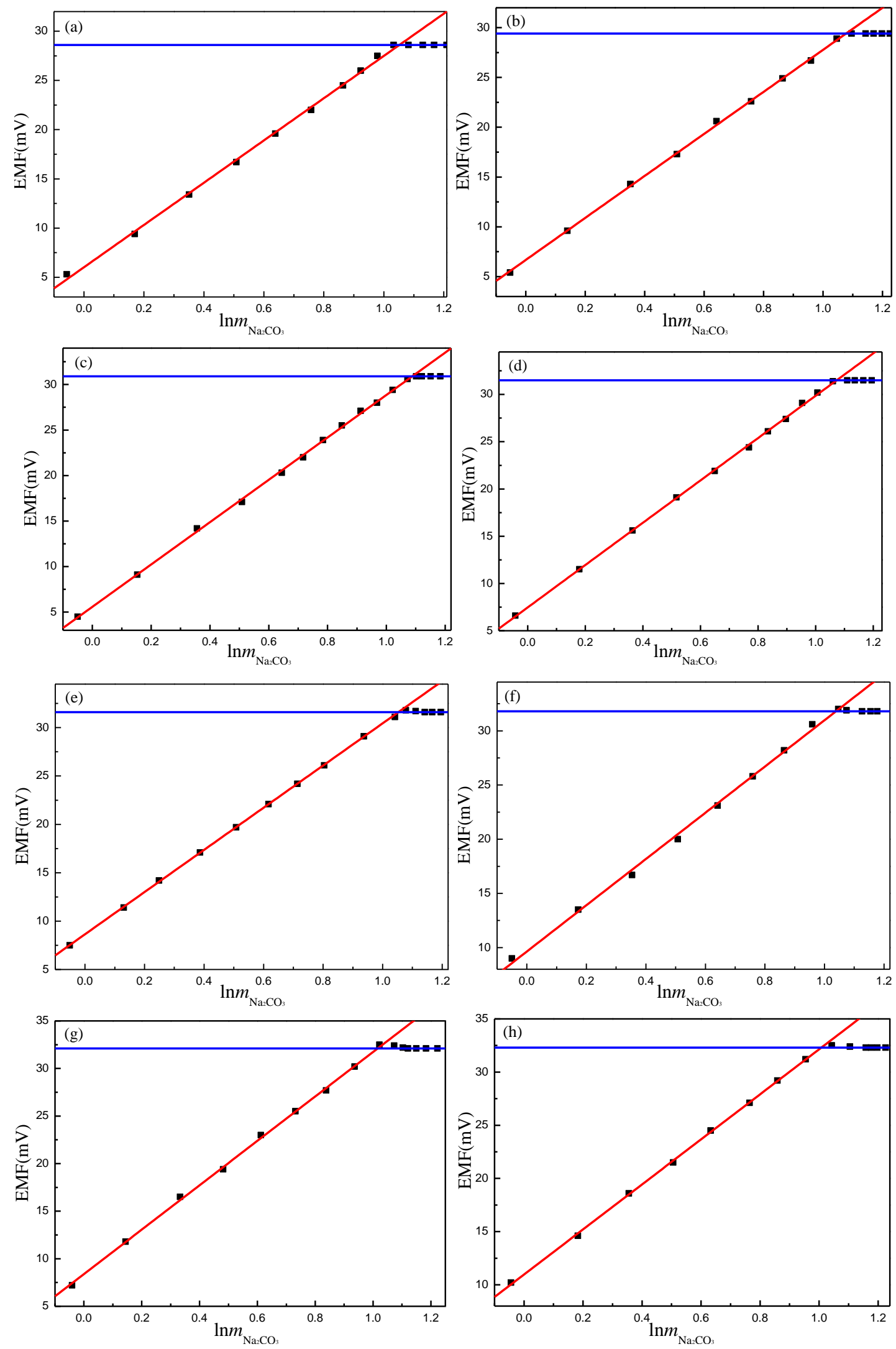

Figure S8. EMF of solution versus logarithmic molality of $\mathrm{Na}_{2} \mathrm{CO}_{3}$ in $200 \mathrm{~g}$ water plus (a) $2 \mathrm{~g}$, (b) $4 \mathrm{~g}$, (c) $6 \mathrm{~g}$, (d) $8 \mathrm{~g}$, (e) $10 \mathrm{~g}$, (f) $13 \mathrm{~g}$, (g) 16g, and (h) 20g SDS solutions at $298.15 \mathrm{~K}$. The lines and symbols have the same meaning as in Figure S1. 

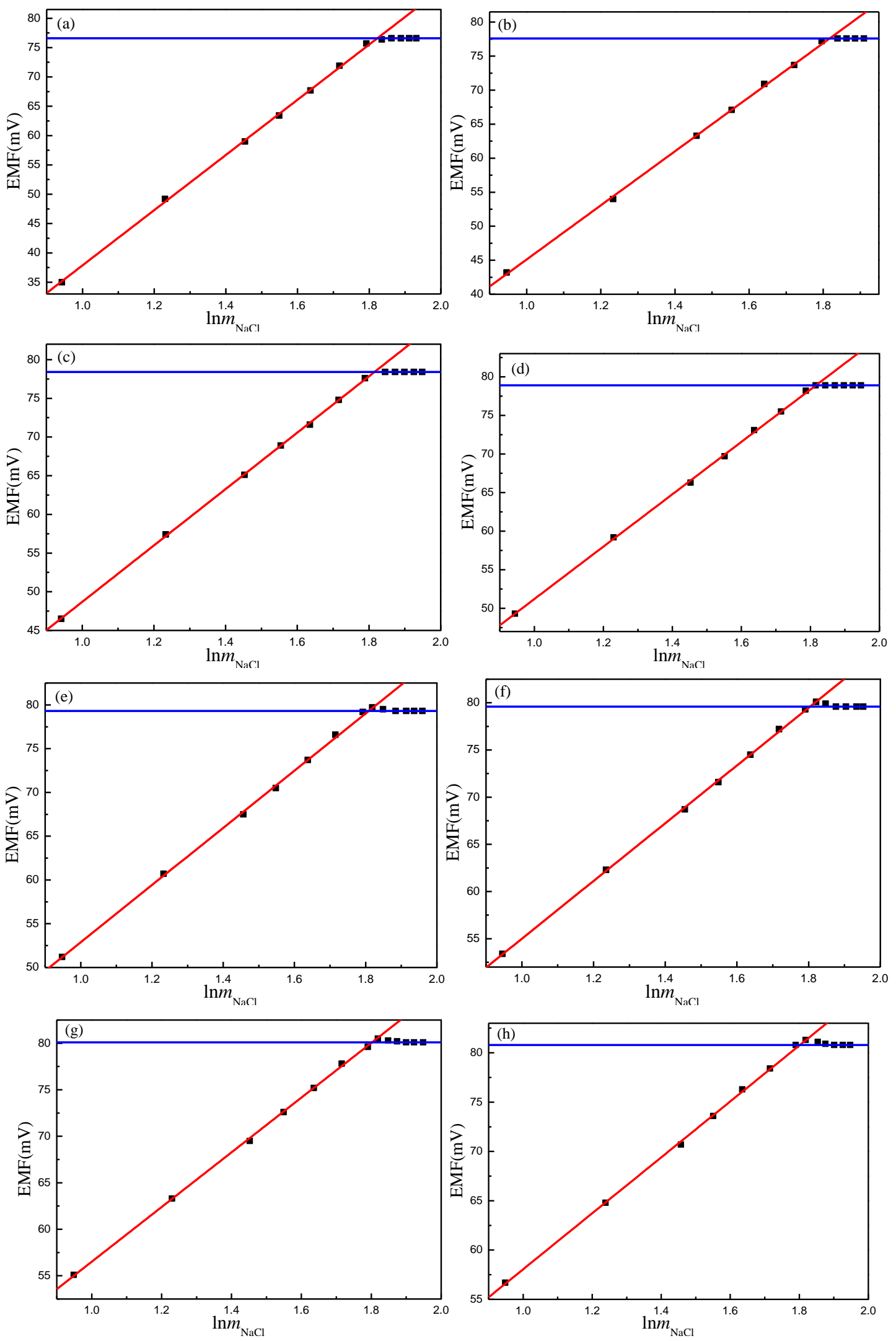

Figure S9. EMF of solution versus logarithmic molality of $\mathrm{NaCl}$ in $200 \mathrm{~g}$ water plus (a) $2 \mathrm{~g}$, (b) $4 \mathrm{~g}$, (c) $6 \mathrm{~g}$, (d) $8 \mathrm{~g}$, (e) $10 \mathrm{~g}$, (f) $13 \mathrm{~g}$, (g) 16g, (h) $20 \mathrm{~g}$ SDS solutions at 298.15 $\mathrm{K}$. The lines and symbols have the same meaning as in Figure $\mathrm{S} 1$. 


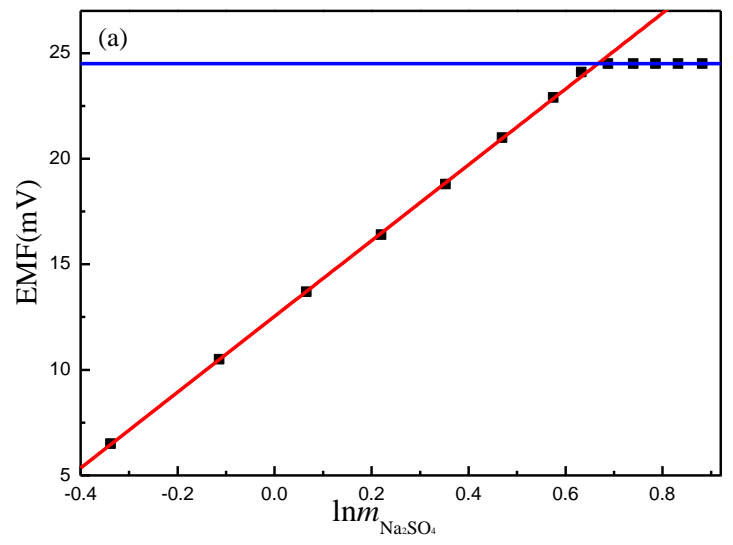

(a)

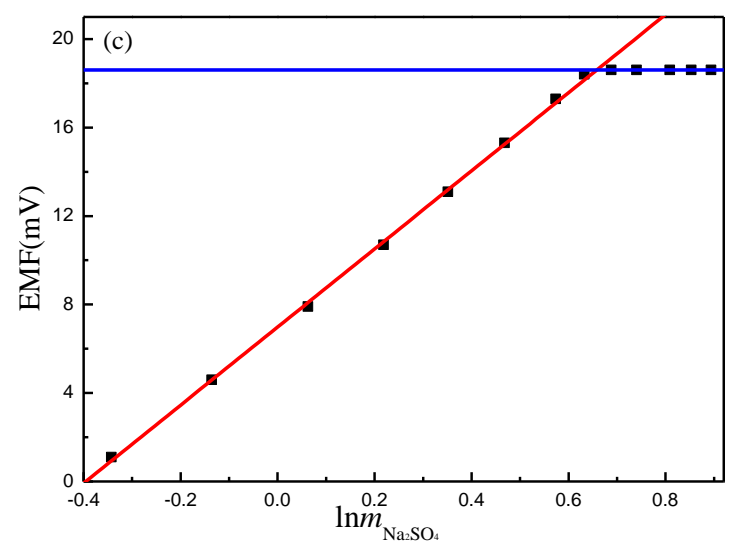

(c)

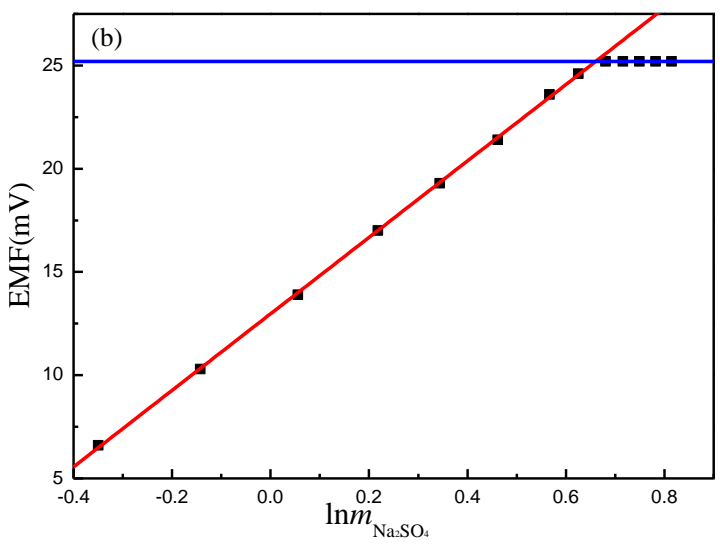

(b)

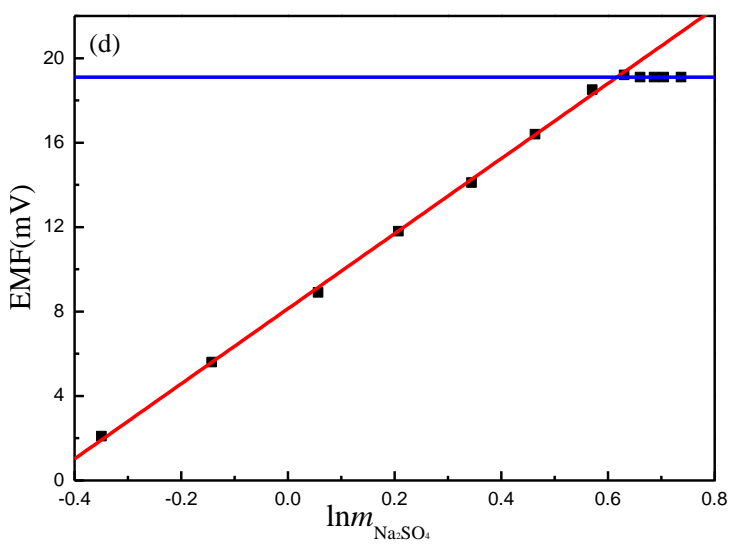

(d)

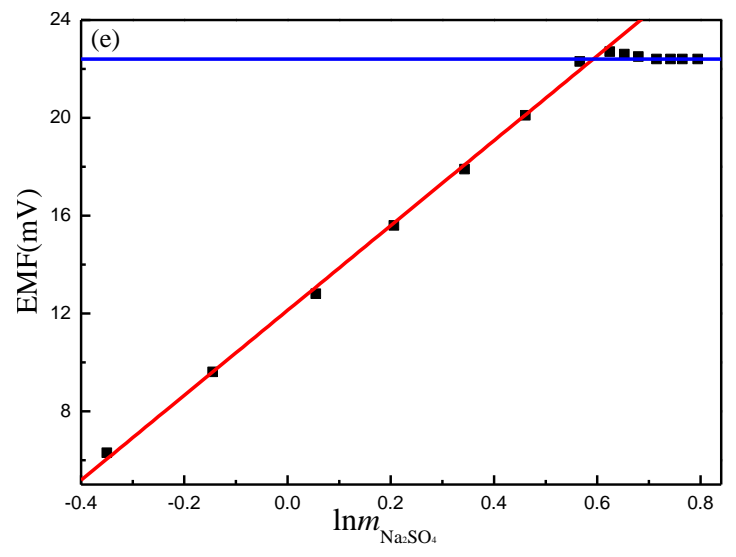

(e)

Figure S10. EMF of solution versus logarithmic molality of $\mathrm{Na}_{2} \mathrm{SO}_{4}$ in $200 \mathrm{~g}$ water plus (a) 2g, (b) 4g, (c) 6g, (d) 8g, (e) 10g STPP solutions at $298.15 \mathrm{~K}$. The lines and symbols have the same meaning as in Figure S1. 


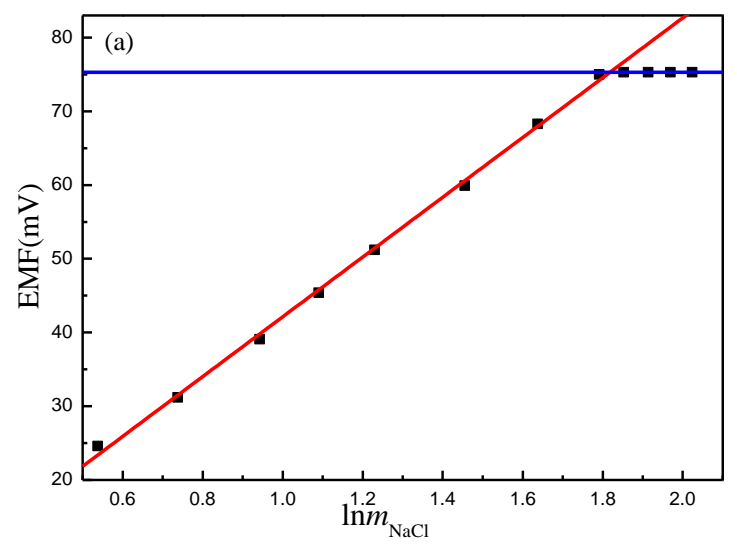

(a)

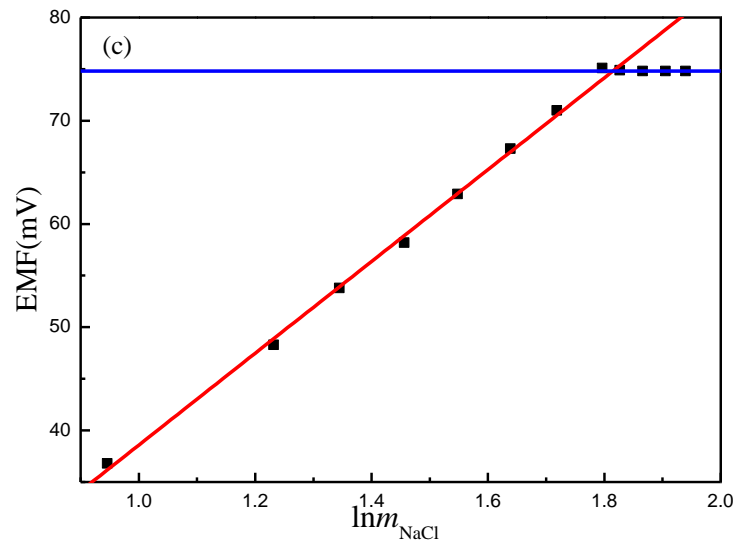

(c)

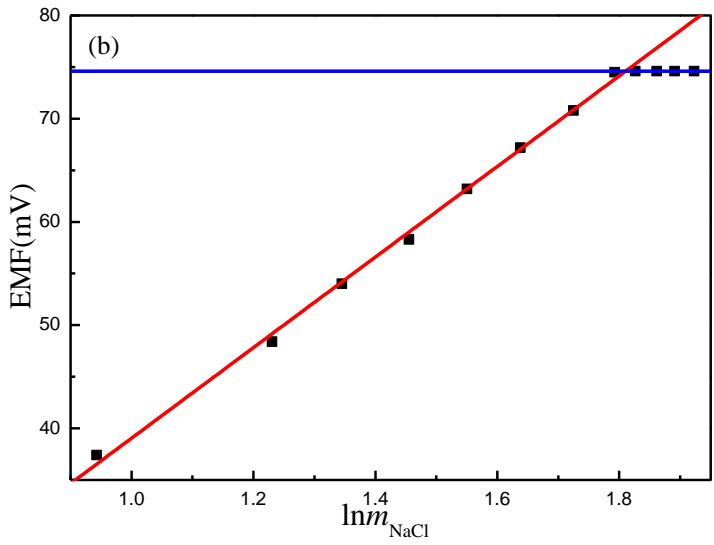

(b)

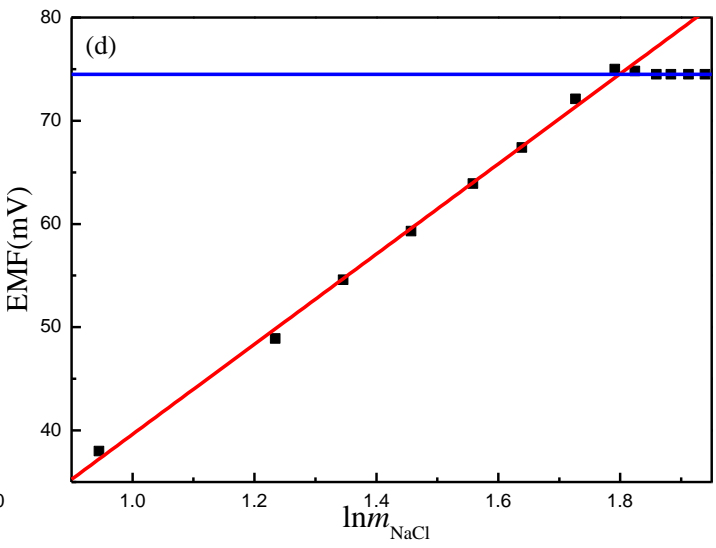

(d)

Figure S11. EMF of solution versus logarithmic molality of $\mathrm{NaCl}$ in $200 \mathrm{~g}$ water plus (a) $2 \mathrm{~g}$, (b) $6 \mathrm{~g}$, (c) $8 \mathrm{~g}$, and (d) $10 \mathrm{~g}$ STPP solutions at $298.15 \mathrm{~K}$. The lines and symbols have the same meaning as in Figure S1. 